\title{
Engaging the Faith Community in Designing a Church- Based Mental Health Screening and Linkage to Care Intervention
}

\author{
Jannette Berkley-Patton ${ }^{1}$, Carole Bowe Thompson ${ }^{2}$, Joah Williams ${ }^{3}$, Kelsey \\ Christensen ${ }^{4}$, Cassandra Wainright ${ }^{5}$, Eric Williams ${ }^{6}$, Andrea Bradley-Ewing ${ }^{7}$, \\ Alexandria Bauer ${ }^{8}$, and Jenifer Allsworth ${ }^{9}$ \\ $1,2,4,8,9$ Department of Biomedical and Health Informatics, University of Missouri-Kansas City School of Medicine, \\ ${ }^{3}$ Department of Psychlogy, University of Missouri-Kansas City, ${ }^{5,6}$ Calvary Community Outreach Network, Health \\ Services and Outcomes Research, ${ }^{7}$ Children's Mercy Hospital
}

Cite as: Berkley-Patton, J., Thompson, C.B., Williams, J., Christensen, K., Wainright, C., Williams, E., Bradley-Ewing, A., Bauer, A., \& Allsworth, J. (2021). Engaging the Faith Community in Designing a Church-Based Mental Health Screening and Linkage to Care Intervention, 32(1), 104-123. DOI: 10.18060/24059

This is an open access article distributed under the terms of the Creative Commons Attribution License.

Editor: Valerie L. Holton, Ph.D.

\begin{abstract}
African Americans are disproportionately burdened by mental health issues (e.g., stress, chronic depression, and post-traumatic stress disorder). Upon review of mental health local/state/national data, a highly-engaged faith-based Community Action Board (CAB) raised concerns about the mental health needs of African Americans and addressed mental health as a priority health area in African American Kansas City churches. African Americans tend to experience barriers to mental health services (e.g., limited access, high cost, mental healthrelated stigma, non-culturally tailored mental health care). African American churches have many strengths that could increase reach, acceptability feasibility, and impact of mental health interventions tailored for African Americans. The CAB conducted a health needs assessment survey ( $N=463 ; 11$ churches) to identify health concerns and potential strategies to inform the design of a church-based mental health intervention. Using a faith-community-engaged approach, the CAB developed the survey and used its findings to design a religiously-tailored, multilevel mental health intervention focused on prevention, screening, and linkage to care. The needs assessment identified intervention strategies (e.g., church-based screening, stress reduction/exercise programs, pastors promoting mental health) that were: (1) rated as highly
\end{abstract}


important/feasible to implement, (2) included in the intervention design, and (3) successfully implemented in African American churches by faith leaders and university students and faculty.

Keywords: mental health, African Americans, mental health screening, linkage to care, churches

\section{Introduction}

African Americans are disproportionately burdened by many mental health conditions compared to European Americans, including generalized anxiety disorder, post-traumatic stress disorder, depression, and substance use (Center for Behavioral Health Statistics and Quality, 2015; González, Tarraf, Whitfield, \& Vega, 2010; Himle, Baser, Taylor, Campbell, \& Jackson, 2009; National Center for Health Statistics [NCHS], 2016a; NCHS, 2016b; Watkins, Assari, \& Johnson-Lawrence, 2015; Williams et al., 2007). African Americans are twice as likely as European Americans to report chronic stress and hopelessness (NCHS, 2016b), due to a myriad of factors (e.g., perceived discrimination, low incomes, and daily/family stressors) (Kasper et al., 2008; Mezuk et al., 2010; Williams \& Mohammed, 2009). They are also more likely to experience greater disability and impairment (e.g., physical and social functioning) in response to mental health illnesses than European Americans (Hankerson et al., 2011).

Yet, African Americans tend to be less likely to seek screening and receive health services for mental health-related issues and disorders (Agency for Healthcare Research and Quality, 2010), are more likely to use the emergency department for mental health treatment (SAMHSA, 2015), and are more likely to not take their medications and drop out of mental health treatment than most other races. (Delphin-Rittmon et al., 2015). A primary barrier for African Americans seeking mental health services is mental health-related stigma (E. Ward, Wiltshire, Detry, \& Brown, 2013). Several studies have found that African Americans tend to have greater negative perceptions of people living with mental health illness and are more suspicious of mental health services than other ethnic groups (Brown, 2004; E. Ward et al.; E. C. Ward, Clark, \& Heidrich, 2009). Other barriers include limitations in health insurance, healthcare access, mental health literacy, and referrals/linkages to mental health services (Briggs, Briggs, Miller, \& Paulson, 2011; Cruz, Pincus, Harman, Reynolds III, \& Post, 2008; Rogers, 2007; E. C. Ward et al.). There is a tremendous need to increase the reach of mental health screening, prevention, and linkage to care (LTC) interventions with African Americans in collaboration with trusted settings such as African American churches, especially considering African Americans tend to be high churchattenders and consider religiosity to be highly important in mental health coping (Pew Research Center, 2015; Rogers, 2007; E. C. Ward et al.).

Collaborative partnerships between urban universities and faith communities have potential to drastically expand the urban university mission of civic engagement (Caret, 2019) to address

(C) The Author 2021. Published by the Coalition of Urban and Metropolitan Universities. www.cumuonline.org

Metropolitan Universities | DOI 10.18060/24059 | February 15, 2021 
health inequities in urban communities of color. Religious institutions often provide a "public face" for communities by providing leadership in the struggle for social justice and equality, including equal healthcare access (Idler, Levin, VanderWeele, \& Khan, 2019). Illustrating the potential of such partnerships, the authors used a community-based participatory research (CBPR) approach to fully engage the Kansas City (KC) FAITH Community Action Board $(\mathrm{CAB})$ in designing a mental health screening, prevention, and LTC intervention in African American churches for implementation by trained church leaders. Additionally, undergraduate/graduate level students from the University of Missouri-Kansas City (UMKC) were trained to assist in implementing the church-based activities (e.g., participant recruitment, mental health screenings) to provide an immersive experience and broaden their understanding of health disparities, social determinants of health, and community-engaged research while participating in meaningful service learning in underserved communities.

The design of the intervention was guided by a health needs assessment (HNA) process. HNAs have traditionally been used to gather information about health concerns from community groups to identify health priorities and determine potential solutions (e.g., Sharma, 2000). Information is also generated on the feasibility to implement identified, important solutions/strategies that can achieve meaningful improvements in proximal health outcomes and possibly, ultimately shift community-level indicators when taken to scale.

The purpose of this paper is to discuss HNA processes that led to the development of the Healthy Actions to Impact Mind and Soul (AIMS) project, an intervention designed to improve prevention, screening, and LTC regarding mental health vices in the African American church context. Here, key CAB HNA activities are discussed and include: (a) development of the HNA survey and assistance with recruiting churches for survey participation, (b) review of the HNA survey findings, (c) determination of important, feasible strategies to increase uptake of mental health screening that could be implemented via a faith-health-academic partnership, and (d) design of the resulting church-based mental health intervention that was eventually implemented by jointly by African American faith leaders and university students.

\section{Methods}

\section{Background}

The KC FAITH CAB is co-led by the study team and the Calvary Community Outreach Network $(\mathrm{CCON})$, a leading faith-based organization with a mission of mobilizing churches to improve African American health in the urban $\mathrm{KC}$ area. The $\mathrm{CAB}$ consists of over 50 members from faith (primarily), health, and academic organizations. The CAB was formalized in 2012 - six years after the study team began conducting several National Institute of Health (NIH) and localfoundation supported research projects in collaboration with CCON and African American 
churches. Over this time, trust and mutual respect was established and reinforced from the study team. Trust-building efforts included fully engaging faith-based partners in the research - even in conceptualization of the research focus, sharing grant dollars via contractual agreements, and sharing in publications and dissemination of study findings, consistent with CBPR principles (Israel, Eng, Schulz, \& Parker, 2013). This work also aligns with UMKC's strategic plan, which includes a focus on transformational undergraduate/graduate education through service to the community and transformational enhancements to social, cultural, health, and economic prosperity in KC's metropolitan area. Engaging students and the faith community in addressing health disparities enhances students' experiential education, collaboratively increases capacity to sustain the work in community settings, and helps to accomplish these university goals.

As guided by CBPR principles (e.g., forming academic/community partnerships, tapping community strengths, ensuring community representation in research processes, identifying key community concerns) (Israel, Eng, Schulz, \& Parker, 2013), the KC FAITH CAB is highly engaged in all phases of the research from setting the research agenda, designing/implementing health promotion interventions, interpreting/disseminating study findings, and sustaining interventions. The CAB's highly active meetings are used to identify/discuss emerging health issues, create and culturally-religiously tailor church-based intervention components, establish appropriate recruitment strategies and study procedures for church settings, make sense of survey and intervention findings, forge new collaborative relationships between CAB members' organizations, and identify and implement strategies to maintain interventions that have been proven to be effective. The $\mathrm{CAB}$ meetings are held quarterly, last two hours with lunch served, and regularly have about 30 members in attendance.

\section{Development of the HNA Survey and Inclusion of Mental Health Items}

Development of the HNA survey has been described extensively elsewhere (Berkley-Patton et al., 2018) and is briefly described here with a focus on how the CAB addressed mental health. Two $\mathrm{CAB}$ meetings were used to discuss/review health disparities from national, regional, and local data sources along with members' lived experiences and personal knowledge. $\mathrm{CAB}$ members initially determined the HNA survey would focus on five health conditions: diabetes, heart disease/stroke, homicide/violence, HIV/AIDS, and asthma. However, after several CAB members expressed the need to address mental health, healthcare access, and strategies specific to faith-based settings, these items were added later and resulted in eight focus areas for the HNA survey. $\mathrm{CAB}$ members divided into subgroups and discussed disparities data relevant to their focus area and generated a list of potential strategies that together could make improvements in that area. This process generated 110 potential strategies across the eight focus areas that were included in the HNA survey. Twelve of the strategies focused on mental health (e.g., support families, provide stress reduction activities, provide counseling services). 
The study team used this information to draft the HNA survey, and used another CAB meeting to do member-checking on wording and survey items, which confirmed the inclusion of questions on receipt of depression/mental health screenings and diagnosis, receipt of services from a mental health professional and from a religious leader, and exposure to community violence. Once the survey document was finalized, faith-based CAB members helped the study team to connect with African American church pastors, provide information about the survey, and determine interest in their church's participation in having members complete the survey (see HNA Survey Procedures below). Based on survey results, initial priorities were identified as diabetes and heart disease/stroke. The CAB then proceeded to design a diabetes/heart disease/stroke prevention, screening, and LTC intervention (Project Faith Influencing Transformation [FIT]), which was been pilot tested. FIT is now a free weight loss and physical activity program based in African American churches in KC urban areas (Berkley-Patton et al., 2020) and is led by faith leaders paired with UMKC students serving as health coaches.

\section{HNA Survey Procedures}

Pastors who were interested in their church participating in the survey provided permission for the study team to share study information and conduct recruitment for the HNA survey with their church members. Church members consented and completed surveys immediately after Sunday morning and Wednesday night church services in sanctuaries and fellowship halls. Study procedures and materials were approved by the UMKC Institutional Review Board. The HNA survey included measures on demographics, health-related behaviors, health screenings (e.g., blood glucose, blood pressure, depression/mental health), and health condition diagnoses (e.g., diabetes, high blood pressure, depression/mental health), receipt of counseling from a pastor/religious leader (ever), receipt of mental health services from a mental health professional, and experiences with homicide/violence. Participants were also asked to rank African American health disparities (diabetes, heart disease/stroke, homicide, HIV/STDs, mental health, and asthma) in order of importance. Additionally, they were asked to rate potential health promotion strategies on degree of importance and feasibility (e.g., 1 = Very Unimportant at all to 5=Very Important), with strategies grouped by each health disparity issue and health care access and church services strategy categories. Descriptive findings (frequencies and means) specific to mental health are reported below.

\section{Results}

\section{HNA Mental Health-Related Findings}

Eleven churches (membership sizes of 50 to 750 members) from the Kansas City, MO and Kansas City, KS urban areas participated in the HNA survey. Among the 463 HNA survey 
participants, 449 were from the participating church members and 14 were CAB members who were not a member of a participating church. Due to missing gender data for seven participants, findings reported are on the remaining 456 participants ( $73 \%$ female; mean age $45, \mathrm{SD}=16$; age range from 18-93). Overall, $9 \%$ had received a depression/mental health screening in the last year, and $11 \%$ had been diagnosed with depression/mental health condition at some point in their lifetime. Other participant characteristics are shown in Table 1.

\section{Mental health-related findings}

$56 \%$ of participants had visited a mental health professional at some point in their lifetime, and $49 \%$ had received counseling from a pastor or a religious leader. Also, $49 \%$ had been a victim of a violent crime (gun shot, physical fight, assault), and $52 \%$ had lost a family member/friend to homicide. These findings were reviewed with the $\mathrm{CAB}$.

Table 1. Participant Characteristics ( $N=456)$

\begin{tabular}{lr}
\hline Participant Characteristic Variables & $\%$ (n) or Mean \pm SD \\
\hline Gender & $73.2 \%(334)$ \\
Female & $26.8 \%(122)$ \\
Male & $45.3 \pm 16.35$ \\
Age (mean \pm SD) & \\
Race & $96.7 \%(436)$ \\
$\quad$ Black/African American/Mixed Race with African & $3.3 \%(15)$ \\
American & \\
Other & \\
Marital status & $59.5 \%(275)$ \\
Single/Separated/Divorce/Widowed & $40 \%(185)$ \\
Married/ Living with partner & \\
Education & $6.0 \%(27)$ \\
Less than high school degree & $23.5 \%(106)$ \\
High school degree/GED & $34.4 \%(155)$ \\
Post high school technical training & $13.7 \%(62)$ \\
Some college & $22.4 \%(101)$ \\
College degree or higher & \\
Health coverage* (categories not mutually exclusive) & $18.1 \%(83)$ \\
Medicare & $10.7 \%(49)$ \\
Medicaid & $49.2 \%(226)$ \\
Private Insurance & $10.5 \%(48)$ \\
Other Health Care & $22.9 \%(105)$ \\
No Insurance & $2.4 \%(11)$ \\
Don't Know & \\
Average monthly income &
\end{tabular}


The $\mathrm{CAB}$ also reviewed the ratings on importance/feasibility for the proposed health promotion strategies for mental health, healthcare access, and church-based activities to determine which strategies would be most impactful on improving mental health and promoting mental health screening with faith-based partners. HNA findings for these three focus areas are shown in Table 2. The top strategies in each of these three focus areas received the most attention in discussions. Among the mental health strategies, providing support to and enhancing communication with families, counseling services, and coping and stress reduction activities were highly rated as important and feasible in faith-based settings. Regarding healthcare access, providing linkage to affordable healthcare services, health fairs inclusive of screenings, support for churches' health ministry and training church leaders to be community health workers, text/email and other messages along with other communications (e.g., social media) were among highly rated strategies. Lastly, highly rated church-based activities included providing free health screenings, health professionals in church services discussing screening importance/procedures, risk checklists, and printed materials (e.g., church bulletins, health resources).

Table 2. Ratings on Importance and Feasibility of Proposed Health Promotion Intervention Strategies on Mental Health, Healthcare Access, and Church-Based Activities
Proposed Health Promotion Strategies by Health
Importance $^{1} \quad$ Feasibility $^{1}$
Disparity Issue ${ }^{1}$
(Average) (Average)

\section{Mental Health}

1. Offer classes on how to strengthen family relationships and communication.

$4.2 \quad 4.0$

2. Provide education on coping and stress reduction skills for youth and adults.

$4.1 \quad 4.0$

3. Provide church-based counseling services for individuals and families.

$4.1 \quad 3.9$

4. Assist families who are helping family and friends living with a mental illness.

$4.1 \quad 3.9$

5. Offer classes to reduce stress and express emotions like drawing, music, yoga, and meditative prayer classes.

$\begin{array}{ll}4.1 & 3.9\end{array}$

$\begin{array}{lll}\text { 6. Promote/offer mental health substance abuse programs. } & 4.1 & 3.8\end{array}$ 
7. Offer ongoing education seminars for church and community members on anxiety, depression, suicide, $4.1 \quad 3.8$ traumatic events, substance use, and eating disorders.

8. Provide educational seminars on managing medication adherence and possible side effects.

$4.0 \quad 3.8$

\section{Health Care Access}

1. Link uninsured persons to low-cost health insurance and free health services.

$4.2 \quad 3.9$

2. Provide churches with procedures and checklists to easily organize church-based health fairs, health

$\begin{array}{ll}4.1 & 3.9\end{array}$ screenings, and immunization events.

3. Provide training/support for churches to develop/sustain health ministries.

$\begin{array}{ll}4.1 & 3.9\end{array}$

4. Use social media and other communication strategies (phone/text/email messages, church announcements) to encourage African Americans to seek regular health screenings, get immunizations, and engage in healthy behaviors.

5. Train church members to be community health workers to assist others with their health care needs (e.g., provide health referrals, coach on health behaviors, attend doctor appointments, provide emotional support).

6. Use social marketing to broadcast health promotion messages about health disparities through billboards, radio, social media, and church websites.

7. Provide members with adequate transportation to health care services.

$\begin{array}{ll}4.1 & 3.7\end{array}$

8. Educate church and community members on preparing for medical visits (having list of questions, medications, and vitamins) to receive high quality care.

\section{Strategies to Address Health Disparity Issues during Church Services}

1. Provide free health screenings (e.g., blood pressure, cholesterol, blood glucose [sugar], HIV/STDs, BMI) and risk assessments.

2. Use church websites to host health disparity information and videos.

$\begin{array}{ll}4.1 & 3.9\end{array}$ 
3. Distribute risk checklists to church and community members to determine their level of risk for each health issue that burdens African Americans.

4. Distribute directories with lists of resources for each health disparity issue.

$4.0 \quad 3.9$

5. Distribute church bulletins, brochures, fact sheets, and posters on each health disparity issue.

$4.0 \quad 3.9$

6. Have trained health workers who provide health screenings/ immunizations to fully describe the $4.1 \quad 3.8$ screening/immunization process in church services.

7. Provide vaccinations for flu, pneumonia, shingles, and other adult illnesses.

$\begin{array}{ll}4.0 & 3.8\end{array}$

8. Have motivational messages from the pulpit and in church calendars to encourage members to seek regular health screenings and immunizations.

${ }^{1}$ All items had importance and feasibility response items ranging from 1 to $5 ; 5=$ very important/feasible.

\section{CAB Discussion and Design of a Church-based Mental Health Intervention for African Americans}

\section{CAB Discussion}

Key topics intensely discussed by the $\mathrm{CAB}$ focused on: (1) limited availability of mental health screening and counseling services (e.g., difficulty in getting an appointment, high cost of services); and (2) the pervasive mental health stigma in African American church settings (e.g., church folk talking negatively about people with mental health issues, fear of screening outcomes, beliefs that believers can pray mental health issues away). Notably, there were lively discussions on spiritual versus clinical diagnosis of mental health issues. Some faith leaders expressed their beliefs that mental health issues can arise from worldly influences and sinful behaviors intended to "rob people of their joy and contentment." Other CAB members, especially those who were behavioral health clinicians and identified as persons of faith, discussed the science of mental health illness and how professional treatment and/or engagement in stress reduction and physical activities could help many mental health issues. In co-leading the discussion with CCON per CBPR principles, the study team encouraged $\mathrm{CAB}$ faith leaders and clinicians to openly express their opinions as a way to share scientific information and cultural perspectives, and ensure the intervention design would be grounded in science while respectfully addressing religious beliefs that could facilitate/ hinder uptake of mental health screening. Additionally, CCON faith leaders helped lead a CAB discussion on how some beliefs among people of faith could further exacerbate or alleviate mental health-related stigma. These 
discussions resulted in the $\mathrm{CAB}$ agreeing on the need for comprehensive religiously-appropriate intervention strategies (e.g., pastoral support in promoting/normalizing screening, church-based Christian yoga, church bulletins on mental health myths/facts and compassion for people living with mental health illness). They also stressed the importance of church-based mental health screening and LTC to assist in overcoming barriers to receiving services. Additionally, the CAB further identified community resources needed to develop, implement, and sustain the selected intervention strategies. This included bringing on UMKC's Community Counseling and Assessment Services as a health agency partner that could provide affordable, sliding scale-fees for counseling by trained/supervised clinical health psychology and counseling education doctoral students. Additionally, KC CARE Health Center was included as a health agency partner to provide community health workers who could assist church-community members with LTC services.

\section{Design and launch of the mental health intervention by faith leaders}

The CAB finalized the church-based intervention design with a focus on prevention, screening and LTC and named the intervention Healthy Actions to Improve Mind and Spirit (AIMS). Determined by the CAB, the primary aim of Healthy AIMS was to increase receipt of mental health screening among African American church-community members. They also sought to: (a) reduce mental health stigma; and (b) increase risk reduction behaviors (exercise and breathing), reduce stress/anxiety, and increase use of LTC services (secondary outcomes).

The Healthy AIMS project was piloted in four Kansas City, MO urban churches, randomized to the religiously-tailored Healthy AIMS intervention or a non-tailored educational comparison arm in 2019. Church leaders were trained to deliver Healthy AIMS components through multilevel church-delivery outlets, as guided by socio-ecological models (e.g., Bronfenbrenner, 1979). Key intervention components are shown in Figure 1 below and include: (a) promotion of healthy behaviors with church and community members through church outreach ministries using text/email messages (church-community level), (b) print materials (e.g., mental health risk checklists, responsive readings, brochures, church bulletins) packaged in a Healthy AIMS Tool Kit; pastors' promotion of physical activity, stress reduction, and mental health screening; and church-based mental health screenings (e.g., anxiety, depression, substance use) by UMKC clinical health psychology students (church services level), (c) Mental Health First Aid training with health ministry leaders and exercise classes (e.g., Christian yoga, Zumba) (group level), and (d) 90-day linkage to mental health services and community resources provided by a community health worker (individual level). Church-community members with screening results that indicated the need for further follow-up were referred to UMKC's Community Counseling and Assessment Services. As customary to the CAB's launch of new projects, a celebration was held to acknowledge the commitment and high-engagement of the CAB in developing and launching Healthy AIMS. 
Figure 1. The Religiously-tailored Multilevel Healthy AIMS Intervention

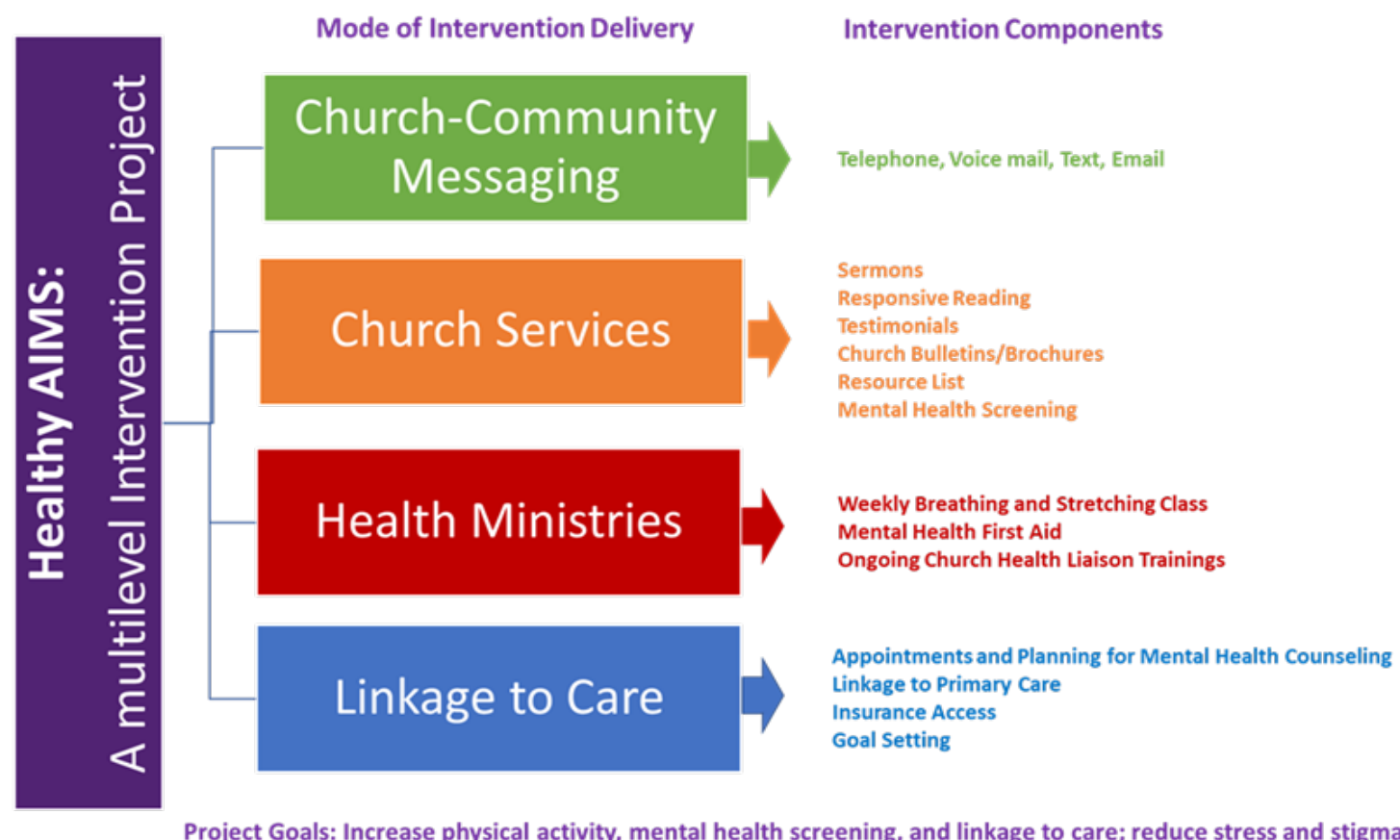

\section{Discussion}

As mental health concerns increase among African Americans due to everyday chronic stressors and diseases, grief from community violence, and young adult suicide (Clements et al., 2020; Compton, Thompson, \& Kaslow, 2005; Hollingsworth et al., 2017; Howard et al., 2016; Patton, Woolley, \& Hong, 2012), there is a growing need to reach African American populations who may be at risk for mental disorders in venues that are highly frequented and trusted. Urban universities are well-positioned to be key partners in these efforts to reach underserved populations with the goal of creating social change and eliminating health disparities in local communities (Peterson, 2014). Faith-based settings have long been acknowledged as a setting that can have tremendous reach with African American congregants (Campbell et al., 2007; Derose et al., 2019) and the community members they serve through church outreach ministries, particularly with prevention health screening interventions (Berkley-Patton et al., 2020; BerkleyPatton et al., 2018; Derose et al., 2019; Resnicow et al., 2004; Sattin et al., 2016). Thus, academic/faith-based organization partnerships are a vital means of addressing health and social issues in urban areas throughout the country. 
Findings from the HNA indicated that $9 \%$ of participants had received a depression/mental health screening in the past year, and $11 \%$ had been diagnosed with depression/another mental health problem at some point in their lifetime, which is consistent with past studies with African American populations (Himle et al., 2009; Williams et al., 2007). Depression rates are often higher among African Americans experiencing frequent racial discrimination (Hudson, Neighbors, Geronimus, \& Jackson, 2016). Additionally, 56\% of participants met with a mental health professional at some point in their lifetime, and early $50 \%$ met with a spiritual leader about mental health concerns. Other studies have found similar results regarding use of counseling services from religious leaders (Chatters et al., 2011), and suggest the appropriateness of equipping these leaders with training, tools, and resources to support their efforts in meeting the mental health and spiritual needs of their members while also referring them to professional mental health services. The National Institute of Mental Health and other national mental health organizations have recognized the importance of faith leaders, particularly in African American communities, and their ability to reach many underserved persons who would not otherwise seek mental health services (National Alliance on Mental Illness, 2016). Future research is needed on how trained faith leaders can improve access to mental health services and positive mental health outcomes with church-community members. Also, future practice is needed on how universities with clinical health psychology and/or counseling education programs, and community-focused mental health clinics can collaborate with faith leaders to support and sustain these efforts.

Recent studies have shown that appropriate tailoring of health promotion interventions to address health disparities can achieve improved health outcomes (Burton, White, \& Knowlden, 2017; Lucas, Manning, Hayman, \& Blessman, 2018), and that tailoring is best accomplished when community stakeholders are involved in establishing the research agenda, participating in the formative research, and contributing to the design of culturally appropriate study procedures and intervention components (Israel et al., 2013). The highly active CAB generated many potential feasible and important faith community strategies to enhance reach and mental health outcomes. Our survey findings indicated that provision of counseling services and screenings, training on stress reduction and coping, and seminars on mental health were top strategies deemed to be highly important and highly feasible to implement in African American faith communities.

These top strategies were then incorporated as components in the resulting faith-based mental health Healthy AIMS intervention, which was recently delivered by trained church leaders to their members through multilevel church outlets (e.g., church services, ministry groups). This intervention reflects a larger, global interest in how faith organizations can function as religious health assets in their communities, that is, resources that can be used to deal with health crises and concerns (Cochrane, 2006). Such interest has given way to large multinational efforts to examine the functional capacity of religious institutions to serve as health care resources, such as the International Religious Health Assets Programme (IRHAP), an international workgroup of scholars and practitioners working to better understand the intersection of faith and public health. 
This work joins a larger body of literature suggesting that faith communities can serve as valuable partners in developing strategies for addressing health disparities.

Of note, using a CBPR approach can be especially important when the health priority of interest is associated with stigmatizing beliefs that can thwart acceptability and feasibility of methods used and uptake of the resulting intervention (Corrigan, 2020; Michalak et al., 2016). To tap the many strengths of African American faith-based settings and tackle mental health stigmatizing beliefs, the authors highly engaged faith leaders along with health agency partners in every phase of the HNA process. At times, there were very different viewpoints on the clinical and spiritual aspects of mental health that were displayed in lively debates. These debates were fruitful and generative, since similar and differing viewpoints would have certainly arisen during church leaders' implementation of intervention strategies. Working through the HNA process helped to bring these differing worldview and clinical viewpoints to the surface and prepare faith, academic, health, and community partners to more effectively implement programs in ways to maximize each partner's strengths.

The iterative HNA process is also a testament to building ongoing capacity to address widespread health concerns, particularly with underserved populations (Sharma, 2000). The authors have used the HNA process to address diabetes and physical activity in faith communities. It could also be used to address newly emerging health disparity conditions (e.g., COVID-19). The HNA enabled our faith-health-academic partnership to make quick use of the HNA findings to address mental health while drawing on the strength of our longstanding collaborative relationships. Academic researchers and universities can play a key role in supporting strategic initiatives identified by community partners and helping translate initiatives into action in a timely manner, which is an advantage of CBPR. The team quickly leveraged its partnership with the university-based community counseling clinic and health agency partners. This allowed for both swift protocol implementation and valuable training opportunities for church health leaders and mental health trainees (students) providing church-based mental health screenings. Moreover, mental health trainees at the university's campus clinic receive specialty training in topics related to health disparities and social determinants (e.g., chronic stressors, chronic diseases, grief from community violence, and young adult suicide). Combining science with community lived experiences and shared resources can enhance the ability and capacity of all key stakeholders, academic and community partners, to work together to be responsive to the needs of underserved communities (Israel et al., 2013).

Despite the many success of the HNA process, limitations were existent. First, the information obtained in the HNA was reflective of church members and not necessarily of community members who might otherwise use church-based outreach services. Thus, future work seeking to develop screening and LTC intervention will benefit from the perspectives of community members engaged with the church but not necessarily active in the church. Second, the authors' 
sample consisted primarily of women and older adults. While reflective of past African American church-based studies (Bauer et al., 2019; Berkley-Patton et al., 2020; Christensen et al., 2020), future HNAs should aim to engage more African American men and young adults to gain a better perspective on the needs of these underrepresented populations. Third, due to mental health as highly stigmatized health concern, social reporting may have been occurring, although the findings on self-reported mental health screening and diagnoses were similar to national studies with African Americans (Himle et al., 2009; Williams et al., 2007). Fourth, the HNA results were largely based on survey results. Alternative methodological choices such as focus groups and key informant interviews could also be a useful way to elicit information from key stakeholders about needs and strategies to address those needs in the context of future research. Lastly, the strategies reflect the Fundamental Christian belief system highly represented on the $\mathrm{CAB}$, therefore the resulting intervention may not generalize to other faith denominations and non-African American faith populations. Future efforts to develop and implement churchbased mental health screening programs will need to be modified in light of the unique belief systems represented within each church or place of worship.

\section{Conclusion}

This paper highlights a CBPR-driven approach to developing a mental health prevention, screening, and LTC intervention in African American churches in Kansas City, MO. The authors used a faith community engaged approach and a HNA to identify important and feasible strategies to design and launch the Healthy AIMS intervention in African American churches. Overall, the HNA process highlights how faith-health-academic partnerships can collaborate to identify health priorities of importance to local communities, jointly develop interventions guided by data and experiential knowledge, even in the face of disagreements, and launch religiously-appropriate interventions that can be feasibly implemented by African American faith leaders with the communities they serve. 


\section{Acknowledgements}

The authors would like to thank our many faith-based and health agency partners who contributed to this work and whose leadership and commitment to community health has been incredibly impactful.

\section{Funding Source}

Funding for this project was provided in part by the Health Forward Foundation of Greater Kansas City. 


\section{References}

Agency for Healthcare Research and Quality. (2010). 2010 National Healthcare Disparities Report, Rockville, MD. Retrieved from https://archive.ahrq.gov/research/findings/nhqrdr/nhdr10/index.html

Bauer, A. G., Berkley-Patton, J., Bennett, K., Catley, D., Bowe-Thompson, C., Lister, S., \& Christensen, K. (2019). Dietary Intake Among Church-Affiliated African Americans: The Role of Intentions and Beliefs. Journal of Black Psychology, https://doi.org/10.1177/0095798419887629

Berkley-Patton, J., Bowe Thompson, C., Bauer, A. G., Berman, M., Bradley-Ewing, A., Goggin, K., ...Allsworth, J. E. (2020). A Multilevel Diabetes and CVD Risk Reduction Intervention in African American Churches: Project Faith Influencing Transformation (FIT) Feasibility and Outcomes. Journal of Racial and Ethnic Health Disparities, 1-12. https://doi.org/10.1007/s40615-020-00740-8

Berkley-Patton, J., Thompson, C. B., Bradley-Ewing, A., Marcie, B., Booker, A., Catley, D., ... Petty, T. (2018). Identifying health conditions, priorities, and relevant multilevel health promotion intervention strategies in African American churches: A faith community health needs assessment. Evaluation and Program Planning, 67, 19. https://doi.og/10.1016/j.evalprogplan.2017.10.012

Briggs, H. E., Briggs, A. C., Miller, K. M., \& Paulson, R. I. (2011). Combating persistent cultural incompetence in mental health care systems serving African Americans. Best Practices in Mental Health, 7(2), 1-25. https://doi.org/10.1177/0886109914531957

Bronfenbrenner U. The ecology of human development: Experiments by design and nature. In: Cambridge, MA: Harvard University Press; 1979.

Brown, J. A. (2004). African American church goers' attitudes toward treatment seeking from mental health and religious sources: The role of spirituality, cultural mistrust, and stigma toward mental illness. The University of North Carolina at Chapel Hill,

Burton, W. M., White, A. N., \& Knowlden, A. P. (2017). A systematic review of culturally tailored obesity interventions among African American adults. American Journal of Health Education, 48(3), 185-197. https://doi.org/10.1080/19325037.2017.1292876

Campbell, M. K., Hudson, M. A., Resnicow, K., Blakeney, N., Paxton, A., \& Baskin, M. (2007). Church-based health promotion interventions: evidence and lessons learned. Annu. Rev. Public Health, 28, 213-234.

https://doi.org/10.1146/annurev.publhealth.28.021406.144016

Caret, R. L. (2019). Social responsibility and civic readiness as critical higher education outcomes. Metropolitan Universities, 30(4), 9-16. https://doi.org/10.18060/23551

(C) The Author 2021. Published by the Coalition of Urban and Metropolitan Universities. www.cumuonline.org Metropolitan Universities | DOI 10.18060/24059 | February 15, 2021 
Center for Behavioral Health Statistics and Quality. (2015). Behavioral health trends in the United States: results from the 2014 National Survey on Drug Use and Health. HHS Publication No. SMA 15-4927, NSDUH Series H-50. Retrieved from https://www.samhsa.gov/data/

Chatters, L. M., Mattis, J. S., Woodward, A. T., Taylor, R. J., Neighbors, H. W., \& Grayman, N. A. (2011). Use of ministers for a serious personal problem among African Americans: Findings from the National Survey of American Life. American Journal of Orthopsychiatry, 81(1), 118-127. https://doi.org/10.1111/j.1939-0025.2010.01079.x

Christensen, K., Berkley-Patton, J., Shah, B., Aduloju-Ajijola, N., Bauer, A. G., Bowe Thompson, C., \& Lister, S. (2020). HIV risk and sociodemographic factors associated with physician-advised HIV testing: What factors are overlooked in African American populations? . Journal of racial and ethnic health disparities, 7(1), 121-128. https://doi.org/10.1007/s40615-019-00641-5

Clements, J. M., West, B. T., Yaker, Z., Lauinger, B., McCullers, D., Haubert, J., . . Everett, G. J. (2020). Disparities in diabetes-related multiple chronic conditions and mortality: The influence of race. Diabetes Research and Clinical Practice, 159, 107984. https://doi.org/10.1016/j.diabres.2019.107984

Cochrane, J. R. (2006). Conceptualising religious health assets redemptively. Religion and Theology, 13(1), 107-120. https://doi.org/10.1163/102308012X13397496507900

Compton, M. T., Thompson, N. J., \& Kaslow, N. J. (2005). Social environment factors associated with suicide attempt among low-income African Americans: The protective role of family relationships and social support. Social psychiatry and psychiatric epidemiology, 40(3), 175-185. https://doi.org/10.1007/s00127-005-0865-6

Corrigan, P. W. (2020). Community-based participatory research (CBPR), stigma, and health. Stigma and Health, 5(2), 123. https://doi.org/10.1037/sah0000175

Cruz, M., Pincus, H. A., Harman, J., Reynolds III, C. F., \& Post, E. P. (2008). Barriers to careseeking for depressed African Americans. The International Journal of Psychiatry in Medicine, 38(1), 71-80. https://doi.org/10.2190/PM.38.1.g

Delphin-Rittmon, M. E., Flanagan, E. H., Andres-Hyman, R., Ortiz, J., Amer, M. M., \& Davidson, L. (2015). Racial-ethnic differences in access, diagnosis, and outcomes in public-sector inpatient mental health treatment. Psychological Services, 12(2), 158. https://doi.org/10.1037/a0038858

Derose, K. P., Williams, M. V., Branch, C. A., Flórez, K. R., Hawes-Dawson, J., Mata, M. A., . . . Wong, E. C. (2019). A community-partnered approach to developing church-based interventions to reduce health disparities among African-Americans and Latinos. Journal

(C) The Author 2021. Published by the Coalition of Urban and Metropolitan Universities. www.cumuonline.org Metropolitan Universities | DOI 10.18060/24059 | February 15, 2021 
of racial and ethnic health disparities, 6(2), 254-264. https://doi.org/10.1007/s40615$018-0520-\mathrm{z}$

Glasgow, R. E., McKay, H. G., Piette, J. D., \& Reynolds, K. D. (2001). The RE-AIM framework for evaluating interventions: what can it tell us about approaches to chronic illness management? Patient education and counseling, 44(2), 119-127. https://doi.org/10.1016/s0738-3991(00)00186-5

González, H. M., Tarraf, W., Whitfield, K. E., \& Vega, W. A. (2010). The epidemiology of major depression and ethnicity in the United States. Journal of psychiatric research, 44(15), 1043-1051. https://doi.org/10.1016/j.jpsychires.2010.03.017

Hankerson, S. H., Fenton, M. C., Geier, T. J., Keyes, K. M., Weissman, M. M., \& Hasin, D. S. (2011). Racial differences in symptoms, comorbidity, and treatment for major depressive disorder among black and white adults. Journal of the national medical association, 103(7), 576-584. https://doi.org/10.1016/S0027-9684(15)30383-7

Himle, J. A., Baser, R. E., Taylor, R. J., Campbell, R. D., \& Jackson, J. S. (2009). Anxiety disorders among African Americans, blacks of Caribbean descent, and non-Hispanic whites in the United States. Journal of anxiety disorders, 23(5), 578-590. https://doi.org/10.1016/j.janxdis.2009.01.002

Hollingsworth, D. W., Cole, A. B., O'Keefe, V. M., Tucker, R. P., Story, C. R., \& Wingate, L. R. (2017). Experiencing racial microaggressions influences suicide ideation through perceived burdensomeness in African Americans. Journal of Counseling Psychology, 64(1), 104. https://doi.org/10.1037/cou0000177

Howard, G., Moy, C. S., Howard, V. J., McClure, L. A., Kleindorfer, D. O., Kissela, B. M., . . Safford, M. M. (2016). Where to Focus Efforts to Reduce the Black-White Disparity in Stroke Mortality: Incidence Versus Case Fatality? Stroke, 47(7), 1893-1898. https://doi.org/10.1161/STROKEAHA.115.012631

Hudson, D. L., Neighbors, H. W., Geronimus, A. T., \& Jackson, J. S. (2016). Racial discrimination, John Henryism, and depression among African Americans. Journal of Black psychology, 42(3), 221-243.https://doi.org/10.1177/0095798414567757

Idler, E., Levin, J., VanderWeele, T. J., \& Khan, A. (2019). Partnerships between public health agencies and faith communities. American Journal of Public Health, 109(3), 346-347. https://doi.org/10.2105/AJPH.2018.304941

Israel, B. A., Eng, E., Schulz, A. J., \& Parker, E. A. (2013). Methods for community-based participatory research for health. San Francisco, CA: Josey-Bass.

Kasper, J. D., Ensminger, M. E., Green, K. M., Fothergill, K. E., Juon, H.-S., Robertson, J., \& Thorpe, R. J. (2008). Effects of poverty and family stress over three decades on the functional status of older African American women. The Journals of Gerontology Series

(C) The Author 2021. Published by the Coalition of Urban and Metropolitan Universities. www.cumuonline.org Metropolitan Universities | DOI 10.18060/24059 | February 15, 2021 
B: Psychological Sciences and Social Sciences, 63(4), S201-

S210.https://doi.org/10.1093/geronb/63.4.S201

Lucas, T., Manning, M., Hayman, L. W., \& Blessman, J. (2018). Targeting and tailoring message-framing: the moderating effect of racial identity on receptivity to colorectal cancer screening among African-Americans. Journal of behavioral medicine, 41(6), 747756. https://doi.org/10.1007/s10865-018-9933-8

Mezuk, B., Rafferty, J. A., Kershaw, K. N., Hudson, D., Abdou, C. M., Lee, H., . . Jackson, J. S. (2010). Reconsidering the role of social disadvantage in physical and mental health: stressful life events, health behaviors, race, and depression. American journal of epidemiology, 172(11), 1238-1249. https://doi.org/10.1093/aje/kwq283

Michalak, E. E., Jones, S., Lobban, F., Algorta, G. P., Barnes, S. J., Berk, L., . . Maxwell, V. (2016). Harnessing the potential of community-based participatory research approaches in bipolar disorder. International journal of bipolar disorders, 4(1), 1-9. https://doi.org/10.1186/s40345-016-0045-5

National Alliance on Mental Illness. (2016). Why faith is so important for African American mental health. Retrieved from https://www.nami.org/Blogs/NAMI-Blog/February2016/Why-Faith-Is-Important-to-African-American-Mental

National Center for Health Statistics. (NCHS; 2016a). Health, United States, 2015: With special feature on racial and ethnic health disparities Retrieved from https://www.cdc.gov/nchs/data/hus/hus15.pdf

National Center for Health Statistics. (NCHS; 2016b). Summary health statistics: National health interview survey: 2014, Table A-7. Retrieved from http://www.cdc.gov/nchs/nhis/shs/tables.htm.

Patton, D. U., Woolley, M. E., \& Hong, J. S. (2012). Exposure to violence, student fear, and low academic achievement: African American males in the critical transition to high school. Children and Youth Services Review, 34(2), 388-395.

https://doi.org/10.1016/j.childyouth.2011.11.009

Peterson, T. H. (2014). Reviving and revising the civic mission: A radical re-imagining of "civic engagement." Metropolitan Universities, 25(3), 17-30. Retrieved from: https://journals.iupui.edu/index.php/muj/article/view/20579/20179

Pew Research Center. (2015). American's changing religious landscape. Retrieved from http://www.pewforum.org/files/2015/05/RLS-05-08-full-report.pdf

Plummer, B. (2012). The cost of untreated mental illness in greater Kansas City Retrieved from https://healthforward.org/wp-content/uploads/2015/11/overview-cost-untreated-illnessgreater-kansas-city.pdf

(C) The Author 2021. Published by the Coalition of Urban and Metropolitan Universities. www.cumuonline.org Metropolitan Universities | DOI 10.18060/24059 | February 15, 2021 
Resnicow, K., Campbell, M. K., Carr, C., McCarty, F., Wang, T., Periasamy, S., . . Stables, G. (2004). Body and soul: a dietary intervention conducted through African-American churches. American journal of preventive medicine, 27(2), 97105.https://doi.org/10.1016/j.amepre.2004.04.009

Rogers, G. (2007). Exploring the relationship between religiosity and attitudes towards seeking mental health help among African American churchgoers.

SAMHSA. (2015). Results from the 2014 national survey on drug use and health: Mental health detailed tables. Retrieved from http://www.samhsa.gov/data/population-data$\underline{\text { nsduh/reports?tab }=38 \text {. }}$.

Sattin, R. W., Williams, L. B., Dias, J., Garvin, J. T., Marion, L., Joshua, T. V., . . Narayan, K. V. (2016). Community trial of a faith-based lifestyle intervention to prevent diabetes among African-Americans. Journal of community health, 41(1), 87-96. https://doi.org/10.1007/s10900-015-0071-8

Sharma, A. (2000). A community needs assessment guide: A brief guide on how to conduct a needs assessment: Loyola University Chicago Center for Urban Research and Learning.

Ward, E., Wiltshire, J. C., Detry, M. A., \& Brown, R. L. (2013). African American men and women's attitude toward mental illness, perceptions of stigma, and preferred coping behaviors. Nursing research, 62(3), 185.

https://doi.org/10.1097/NNR.0b013e31827bf533

Ward, E. C., Clark, L. O., \& Heidrich, S. (2009). African American women's beliefs, coping behaviors, and barriers to seeking mental health services. Qualitative health research, 19(11), 1589-1601. https://doi.org/10.1177/1049732309350686

Watkins, D. C., Assari, S., \& Johnson-Lawrence, V. (2015). Race and ethnic group differences in comorbid major depressive disorder, generalized anxiety disorder, and chronic medical conditions. Journal of racial and ethnic health disparities, 2(3), 385-394. https://doi.org/10.1007/s40615-015-0085-z

Williams, D. R., Gonzalez, H. M., Neighbors, H., Nesse, R., Abelson, J. M., Sweetman, J., \& Jackson, J. S. (2007). Prevalence and distribution of major depressive disorder in African Americans, Caribbean blacks, and non-Hispanic whites: results from the National Survey of American Life. Archives of general psychiatry, 64(3), 305315.https://doi.org/10.1001/archpsyc.64.3.305

Williams, D. R., \& Mohammed, S. A. (2009). Discrimination and racial disparities in health: evidence and needed research. Journal of behavioral medicine, 32(1), 20-47. https://doi.org/10.1007/s10865-008-9185-0 